\title{
Educar en la kitá Pardés Alef, un acto de fe
}

\author{
Educating at the kitá Pardés Alef, an act of faith
}

\author{
Patricia Motola Pedroso \\ Majón Albert Einstein de la Comunidad Hebrea de Cuba \\ patriciamotolap@gmail.com \\ Tamara Kely Martino Zagovalov \\ Majón Albert Einstein de la Comunidad Hebrea de Cuba \\ tamarakelymartino@gmail.com
}

\section{Resumen:}

En este artículo se presentará una de las experiencias docentes, la de la kitá Pardé Alef, que cada domingo tiene lugar en el Majón Albert Einstein, en sus sedes del Patronato de la Casa de la Comunidad Hebrea de Cuba y en el Centro Hebreo Sefaradí, la que ha provocado la transformación del ser humano e incidido en su capacidad de hacer tikún olam.

Palabras claves: Educación, educación judía, proceso docente-educativo, formación de valores.

\begin{abstract}
:
The authors of this article present one of the pedagogical experiences, the kitá Pardés Alef, that take place every Sunday in the Majón Albert Einstein, at the Patronato of the Cuban Jewish Community and in the Sephardic Hebrew Center. This pedagogical activity has led to a change in the students as human beings, and it has influenced in their capacity of making Tikun Olam.
\end{abstract}

Keywords: Education, jewish education, teaching-learning process, formation of values.

José Martí comenzaba la dedicatoria de su libro Ismaelillo, dirigida a su hijo, en 1882 con las siguientes palabras:

Hijo:

Espantado de todo me refugio en ti. 
Tengo fe en el mejoramiento humano, en la vida futura, en la utilidad de la virtud, y en ti $(\ldots)^{1}$

Ángel tutelar de la nación, Martí, durante su labor intelectual, propuso paradigmas de vida que tenían a la Isla, a los cubanos y a América como centros y, cuando se vuelve hacia su hijo, es para retomar ideas ya anunciadas en ciernes en su adolescencia, en textos como el Presidio político en Cuba (1871), -relato nacido del dolor, del sufrimiento profundo ante las miserias humanas, que desprecia, sí, pero no odia, no puede-: la identificación con el otro, la compasión por él, la vergüenza de aquellos episodios, el reclamo a la autoridad, el clamor a Dios y la presencia de la fe, a pesar de todo.

Experiencias tan profundas moldearon su sensibilidad, como cuando presencia los desmanes de la esclavitud siendo muy joven. Muchos años después, al entregarse a uno de sus proyectos continentales y nobles, la publicación de una revista para niños -también para los padres-, titulada La edad de oro, afloran su ternura, su fe y la convicción de actuar, en este caso, mediante la educación del hombre. En su prólogo expresa:

(...) Para los niños trabajamos, porque los niños son los que saben querer, porque los niños son la esperanza del mundo (...)

Así queremos que los niños de América sean: hombres que digan lo que piensan, y lo digan bien: hombres elocuentes y sinceros ${ }^{2}$.

Pensar en José Martí a la luz del siglo XXI podría parecer un arcaísmo, una especie de fatiga cognitiva sin embargo, las páginas de este trabajo evidenciarán la fidelidad inevitable al ideario martiano, no solo debido a nuestra formación sino porque, en más de un motivo, ostenta puntos de contacto con los principios y valores del judaísmo, posición también nuestra. Pretenden ser estas palabras, un nuevo acto de confianza en el ser humano, a modo de brújula buscando o llegando a puerto, en medio de los vientos de la posmodernidad, que sacuden el alma en demasía.

Cual Hamlet, aparece el conflicto: ser o no ser o; actuar o no actuar. Tal vez la pregunta debería ser: ¿qué tiene un maestro -función conscientemente profesada por nosotras como axioma de fe- que enseñar a sus alumnos hoy? Quizás muchos responderían: ¿qué maestros, qué alumnos? Deberíamos declarar entonces: impartimos clases en una escuela hebrea. Reaparece el judaísmo en la ecuación. Es necesario reformular la interrogante: ¿cómo tiene un moré $e^{3}$ que enseñar judaísmo a sus talmidim ${ }^{4}$ hoy? Volvemos a Martí y resolvemos: ¿para qué debemos educar a nuestros talmidim hoy? Seleccionamos esta última, sabiendo de las combinaciones infinitas. Por el momento, trataremos de brindar las primeras soluciones, humildes propuestas, mediante la ciencia pedagógica.

\footnotetext{
${ }^{1}$ Martí, José. Ismaelillo. Tomado de Poesía completa, La Habana, Ciencias Sociales 2007 p. 17.

${ }^{2}$ Martí, José. La edad de oro. La Habana, Gente Nueva 1959 p. 8

${ }^{3}$ Nota del Editor: Moré, del hebreo, Maestro. Pl. masc. Morim; pl. fem. Morot.

${ }^{4}$ Nota del Editor: Talmidim, del hebreo, pl. masc. estudiantes, alumnos. Sing. masc. Talmid, sing. fem. talmidá. Pl. fem. talmidot.
} 
El Majón ${ }^{5}$ Albert Einstein es un proyecto de la Comunidad Hebrea de Cuba radicado en 2 de las sinagogas de La Habana, el Patronato de la Casa de la Comunidad Hebrea de Cuba y el Centro Hebreo Sefaradí. Las puertas de sus 7 kitot $^{6}$-Shorashim, Nitzanim, Anafim, Prajim, Ilanot, Pardés Alef y Pardés Bet- se abren cada domingo para recibir a más de 150 talmidim, de edades comprendidas entre 4 y 70 años, aproximadamente. Sus clases se organizan en cursos trienales, donde se profundiza de manera paulatina en los contenidos, agrupados en 3 unidades temáticas: Historia del pueblo hebreo y judaísmo, Fiestas y conmemoraciones e idioma Hebreo. Esta actividad educativa es continuadora de aquella iniciada en la escuela Talmud Torá Theodor Herzl (1924), perteneciente a la congregación sefardí Chevet Ahim, y de otras fundadas posteriormente, como hemos comentado en nuestro artículo Caminos de la educación judía en Cuba, publicado en la revista Espacio laical ${ }^{7}$.

La kitá Pardés Alef es un espacio de aprendizaje para adultos mayores de 25 años. En la actualidad está compuesta por 32 talmidim, siendo el grupo etario predominante el de 30-50 años de edad, la gran mayoría profesionales, y prevaleciendo el género femenino. Si bien nuestra labor como morot alcanza los 5 años, algunos de ellos recibieron clases con otros morim tiempo atrás.

Si fuéramos a calificar toda nuestra experiencia docente, diríamos: un reto constante. Han sido años de trabajo intenso, de mucha entrega, de superación de obstáculos, todo lo cual se traduce en un crecimiento personal. Como diría el poeta, "caminante no hay camino, se hace camino al andar". Aquellos inseguros primeros pasos, hoy se han convertido en una carrera de relevo, donde cada talmid es el protagonista y nosotras, las morot, facilitadoras del proceso de aprendizaje. Al no pertenecer a un sistema formal de enseñanza, consideramos el límite mayor de nuestra actividad el propio ser humano, su deseo de conocer, pertenecer, hacer, ser; desafíos constantes.

Una de las particularidades de la práctica docente en este quinquenio, ha sido la elección de un tema central, especie de hilo conductor del curso, orientador de las actividades. El 1er año, 5775 (20142015), pudiéramos calificarlo como un período donde se abordaron asuntos generales de 2 de las 3 unidades comentadas. Debemos precisar que nuestro transitar por el idioma Hebreo no será objeto de estas páginas, si bien está presente en las lecciones dominicales. En el 2do, 5776 (2015-2016), la historia y la identidad del pueblo judío tuvieron primacía; en el 3ero, 5777 (2016-2017), se hizo énfasis en las creencias, la liturgia y las fiestas y conmemoraciones; en el 4to, 5778 (2017-2018), la historia moderna y contemporánea de nuestro pueblo estuvo en el centro de las clases; y en el 5to, 5779 (2018-2019), la identidad y los valores judíos, como el de la responsabilidad, fueron el motor impulsor.

Describir la experiencia docente en este último año lectivo es el deseo del presente artículo, con el fin de dar a conocer las propuestas didácticas desarrolladas en las clases, -donde se ha tenido en cuenta el contexto de nuestra colectividad-, resultados que hablan de la posibilidad de

\footnotetext{
${ }^{5}$ Nota del Editor:: Majon, del hebreo, Centro de Estudios.

${ }^{6}$ Nota del Editor: Kitá, del hebreo, curso, aula. Pl. kitot.

${ }^{7}$ Motola Pedroso, Patricia y Tamara Kely Martino Zagovalov. Caminos de la educación judía en Cuba, Espacio laical \# 3, 2018 pp. 68-73
} 
transformación del ser humano, de entrega y de compromiso a través de la educación. Como planteara José Martí, la instrucción debe acompañarse de un sentido ético; es necesario cultivar inteligencia y virtud al mismo tiempo. Ello, para el judaísmo, es también tikúm olam ${ }^{8}$.

Debe tenerse en cuenta que la pedagogía, ciencia humanística e inexacta, nos ha invitado constantemente a lo largo de nuestro trabajo a revisitar sus principios. Esto, sumado a las características del Majón, de nuestro grupo de talmidim, a sus necesidades y expectativas, y a la capacitación semanal recibida por los morim, coadyuvó a modificar el 5to curso según lo planificado en un inicio, como se apreciará más adelante. Así, la selección del tema respondió en realidad a un proceso más complejo, donde intervinieron disímiles aspectos. Igualmente, la experiencia nos ha demostrado la importancia de atender a los objetivos educativos del aprendizaje, trabajados incidentalmente en años anteriores. En este último, decidimos cambiar el enfoque y centrarnos en ellos de manera especial. Advertimos los resultados obtenidos como una expresión del crecimiento personal y grupal.

Una de las herramientas de gran ayuda para planificar el curso siguiente ha sido siempre la aplicación de una encuesta en los finales del que concluye. Entre los aspectos medidos, está la selección de temas de interés por parte de los talmidim, abordados con posterioridad en las jornadas dominicales. El más solicitado siempre ha sido la actualidad de Israel. Además de este aspecto, en junio de 2018, el grupo había señalado como necesidades las de aprender más sobre historia y judaísmo para continuar ampliando sus conocimientos; realizar actividades relacionadas con la vida de la comunidad hebrea en Cuba fuera de los marcos de la kitá; fomentar la unidad del grupo; y crear espacios de ayuda social y de apoyo económico a la colectividad. Estas respuestas fueron expresadas por más de la mitad de los encuestados y formaron parte de los desafíos del curso.

Otro de los retos que conocíamos estaría presente, porque desde octubre 2017 había comenzado a gestarse, era el curso de regularización, el cual brindaría sus clases de forma paralela a las del Majón y donde estaban inmersos la mitad de nuestros talmidim y una de las morot. En este proceso, a las personas de padre o cónyuge judío, que lo deseen, con una vida activa en la colectividad y tiempo de permanencia en ella, se les brindan clases durante 1 año, para obtener el caudal de conocimiento necesario, -pero donde el componente personal y humano es fundamental-, que avale su posición ante un beit $\operatorname{din}^{9}$. Este decide si están capacitadas o no para formar parte del pueblo de Israel. Ellas deben ser fiel al compromiso establecido. Apoyarlos y guiarlos en ese momento también fue asumido dentro de nuestra labor.

Organizamos el curso entonces en dos etapas: la primera, de octubre a diciembre, desde el inicio de las clases en el Majón hasta el final del curso de regularización, donde el objetivo instructivo estaría orientado a complementar ese proceso. Por ello, valorar los contenidos sobre historia del pueblo hebreo y judaísmo, y fiestas y conmemoraciones marcó el rumbo de nuestras actividades. Estos fueron los temas: fundamentos del judaísmo, símbolos y ciclo de vida, Tanaj, servicios religiosos,

\footnotetext{
${ }^{8}$ Nota del Editor: Tikun olam, reparar el mundo, uno de los valores importantes del judaísmo.

${ }^{9}$ Nota del Editor:bet din, del hebreo: en este caso, especie de "tribunal rabínico", encargado de decidir acerca de la competencia de la persona que decide convertirse al judaísmo.
} 
calendario judío, shabat, festividades, hitos de la historia del pueblo de Israel, personalidades destacadas y kashrut ${ }^{10}$. Muchos de ellos fueron agrupados en varias clases, pues el tiempo era limitado y debía ser provechoso. Pretendíamos además que los talmidim trabajaran a nivel de creación y aplicación, llevando a la práctica lo aprendido. Serían los protagonistas del proceso de enseñanza-aprendizaje.

Para lograr todo lo anterior, nos auxiliamos de diferentes técnicas participativas. Algunas de ellas fueron: la aplicación de verdaderos y falsos para precisar contenidos, generales y específicos; identifícalo, momento donde los talmidim exploraban el lugar, detectaban un símbolo judío, por ejemplo, y exponían al resto del grupo todo lo relacionado con él; creación de puestos o stands donde se promovían varias festividades de manera creativa, como una agencia de viajes o venta de juguetes infantiles; e impartición de clases por parte de los talmidim, orientados por las morot.

Esta última experiencia quisiéramos destacarla, pues en esa sesión se conjugaron aspectos instructivos y educativos del proceso de enseñanza movilizadores de la transformación de la kitá. Independencia, liderazgo, confianza y cooperación fueron algunos de ellos. Casi por primera vez tuvo lugar un intercambio de roles, de talmid, que observa y escucha, a moré, que orienta y explica, y viceversa. En el resto de los participantes hubo un desvío en el foco de atención: ahora debían seguir a sus compañeros, y no a sus morot. En un inicio, el clima resultó raro, extraño, desconcertante sin embargo, a medida que avanzaba la actividad, todos participaban.

Ese día, varios talmidim impartieron los contenidos sobre símbolos, tefilá ${ }^{11}$, sidur ${ }^{12}$ y servicios religiosos en la sinagoga del Patronato de la Casa de la Comunidad Hebrea de Cuba y se apoyaron en preguntas y respuestas al resto del grupo, explicaron y realizaron técnicas de concentración, encaminadas a prepararlos para el beit din y a fomentar la unidad de la kitá. El último momento de la jornada fue un reflejo de ello. Organizados en un maagal ${ }^{13}$, una talmidá hizo la siguiente pregunta: ¿qué le desearías a la kitá? Defínelo con una palabra. Algunas de las respuestas fueron: alegría, integridad, reflexión, unión, continuidad. Al finalizar, e incluso días después, muchos talmidim se nos acercaron para comentarnos lo bien que se habían sentido, cuán significativo había sido el cambio de roles y a agradecernos por haber confiado en ellos.

En la segunda parte del curso, de enero a junio, el objetivo se encaminaba a describir aspectos de la comunidad judía cubana e israelí (siglos XX y XXI), manera de relacionar los contenidos impartidos en años anteriores y de considerar los resultados de la encuesta aplicada. No obstante, las condiciones docentes cambiaron y, con ellas, nuestra planificación. Así, determinamos modificar dicho objetivo. Se reformuló de la siguiente forma: caracterizar la identidad judía y su

\footnotetext{
${ }^{10}$ Nota del Editor: Kashrut, del hebr. Kasher, apto. Está relacionado con las leyes dietéticas exigidas dentro de la halaja (legislación judía), lo que está o no permitido para su consumo. Es importante señalar que "lo apto" excede los limites de la alimentacion, tambien rige para el comportamiento de la persona.

${ }_{11}$ Nota del Editor:tefilá, del hebreo, oración.

12 Nota del Editor: sidur, del hbr. Libro de oraciones.

${ }^{13}$ Nota del Editor:: maga, del hbr. Circulo.
} 
relación con el valor de la responsabilidad, lo cual implicaba sobre todo un abordaje desde un enfoque diferente.

En cuanto a los objetivos educativos, pensamos que debían estar presentes durante todos los meses de estudio del curso lectivo y trabajar en función de fortalecer la identidad judía, desde los vínculos con la historia del pueblo hebreo; fomentar el aporte de los talmidim a la vida comunitaria; y mantener el ambiente de cooperación en la kitá.

Uno de los factores influyentes en los cambios de esta segunda etapa, que contribuyó a alcanzar los objetivos trazados fue el estudio a distancia de las unidades propuestas por la Fundación argentina BAMA para nuestra capacitación como morim. Ello ha implicado para nosotras una transformación como morot y judías. Desde finales del 2017, dicha organización ha guiado nuestro aprendizaje en el tzevet $^{14}$ de morim mediante el curso MIRKAM. Merkazim LeKidum Mejanjim ${ }^{15} \mathrm{y}$, a medida que hemos caminado, hemos tratado de incorporar y enriquecer las clases dominicales con los contenidos recibidos. Tal fue el caso de la unidad 4, Kol Israel arevim ze laze $e^{16}$, dedicada a pensar el valor de la responsabilidad en el judaísmo desde sus orígenes, y al trabajo con los componentes del proceso de enseñanza, estudiada en los primeros meses del curso 5779.

Igualmente, como parte nuestro transitar, en enero y febrero de 2019, nos dispusimos a la construcción de un Mercaz Lemidá ${ }^{17}$, centro de aprendizaje, sobre la historia de la comunidad hebrea de Cuba, información antes recopilada por el tzevet en una monografía, tarea final presentada en el primer año de capacitación. Entre los morim preparamos el espacio para todo el Majón y, nuestros talmidim, como el resto, se enfrentaron a una nueva forma de adquirir los conocimientos. Organizado en 6 estaciones temáticas, donde se proponían actividades para los diferentes grupos etarios: niños, adolescentes y jóvenes, y adultos, cada moré desplegó su creatividad en ellas.

Una de las propuestas consistía en la observación de un video, donde se mostraban varios lugares, pertenecientes antes a familias judías de La Habana y su estado actual. Al finalizar, se instaba a las personas con una pregunta a realizar alguna acción para su rescate. En los talmidim la respuesta fue inmediata: debemos hacer un proyecto social para contribuir a salvaguardar nuestros espacios, idea que, como comentamos, ya era una necesidad sentida. Luego de mucho conversar, hacer evaluaciones, búsquedas, valoraciones determinaron arreglar el área donde debía funcionar el gimnasio comunitario, proyecto detenido hacía unos años. En una de las clases, apoyándonos en algunas de las tareas de MIRKAM, surgió el Proyecto Iluminando Nuestra Identidad, con un logo dibujado y creado entre todos los talmidim, impreso posteriormente en un pullover. El 19 de mayo del 2019, fecha en que se conmemora la caída en combate de nuestro Apóstol José Martí, la kitá

\footnotetext{
${ }^{14}$ Nota del Editor: tzevet, del hbr. Equipo, conjunto.

15 Nota del Editor: Mirkam, Merkazim leKidum Mejanjim es un programa de capacitación en contenidos judaicos para educadores. Este programa presencial-virtual está destinado a educadores tanto del área formal como no formal. El programa está diseñado y es implementado por BAMA-Argentina.

${ }^{16}$ Nota del Editor: frase hebrea, significa Todo Israel es responsable el uno por el otro.

${ }^{17}$ Nota del Editor: Merkaz leMidá, Centro Educativo.
} 
limpió y organizó dicha zona deportiva de la colectividad. De simples espectadores se convirtieron en decisores y protagonistas, contribuyeron con su comunidad; dieron respuestas a sus necesidades; se apropiaron más aún del espacio pedagógico; se fomentó la unidad y la colaboración del grupo, al tiempo que se incidió en valores, individuales y colectivos, como el de la responsabilidad y la solidaridad, y se ha mentido viva la llama para dar continuidad a esta idea.

Como parte de nuestra capacitación, en el seminario presencial, impartido por una de las profesoras de BAMA en octubre de 2018, se nos propuso estructurar la clases en 4 momentos, con una duración aproximada de 20 min cada uno: Mekorot $^{18}$, Identidad, Contenido judaico y ¿Sabías qué? Al llevarla a la práctica, comprobamos, si bien era un reto, facilitaba el desarrollo de las sesiones, la participación y el interés de los talmidim. Así, se impartieron los temas: Mekorot: La creación del mundo; Adam, Eva y la serpiente; Abel y Caín; la Torre de Babel. Identidad: Acontecimientos, instituciones (escuelas y organizaciones) y personalidades (Ricardo Subirana, Ida Glezer de Castiel, Alberto Mechulam Cohen) significativos de la historia de la comunidad hebrea de Cuba. Contenido judaico: Hebreo a partir del estudio de la letra de imprenta mediante el libro 3 del método Phonetic Hebrew Decoding, de Sara Rosen; los pronombres personales, días de la semana y números; y de la expresión oral, la presentación personal. ¿Sabías qué?: Reflexiones sobre la responsabilidad a partir de la aliteración de las raíces de las palabras arev, erev, avar y raav, según el rabino Marcelo Polakoff, de las clases de MIRKAM.

Una de las técnicas empleadas en la impartición de los contenidos, surgida también de una de las actividades de MIRKAM, fue la participación de los talmidim en un sociodrama sobre las actitudes de los hermanos Abel y Caín, contextualizado en una de las problemáticas del campo cubano: la falta de recursos materiales para obtener una buena producción de alimentos. Luego de representar la situación dramática y el fratricidio, se prosiguió a debatir los conflictos expuestos. Fue esta una vía para reactualizar nuestra Torá $^{19}$, promover su acercamiento, y retomar el valor de la responsabilidad desde una perspectiva distinta.

Otras técnicas y actividades también nos ayudaron a trabajar, de manera directa, con los objetivos educativos. Entre ellas queremos mencionar el Poema colectivo, creado en la última parte de la clase del 17 de febrero de 2019, dedicada al Día del Amor y la Amistad. Después de un momento de reflexión, les pedimos confeccionar unos versos entre todos. Quien lo deseara, anotaría sus impresiones teniendo en cuenta lo escrito por el compañero. Si bien no son profesionales de las letras, el contenido de este fragmento ilustra el sentir de nuestros talmidim:

La amistad. Kitá Pardés Alef.

(...)

Amor mutuo y sincero entre nos es verdadero.

Es incondicional, jaranero, comprometido y eterno.

Sin la amistad hubiese sido imposible llegar a donde estamos.

\footnotetext{
18 Nota del Editor: Mekorot. Del hbr. Fuentes.

${ }^{19}$ Nota del Editor: Torá, se refiere al libro fundacional del Judaísmo que, en su parte escrita, corresponde a los 5 primeros libros del texto bíblico comunmente conocido como Pentateuco.
} 
Es amor, entrega y comprensión.

La amistad es como el árbol: no importa lo grande, sino lo profundo de sus raíces.

Esperamos cada domingo con ansiedad y desespero

Estar con un grupo lleno de entusiasmo y

Compartir con alegría el hebreo.

Igualmente, la celebración del Día del Estudiante, de cumpleaños colectivos, y de los cinco años de trabajo en la kitá fueron espacios que contribuyeron a la unidad del grupo y a fomentar la colaboración. Los festejos por nuestro quinquenio como sus morot tuvieron lugar el 16 de diciembre del 2018, debido a la cercanía de la fiesta de Jánuca ${ }^{20}$, vinculada también con la educación, y al cierre del curso de regularización. Una de las técnicas realizadas ese día fue la Rifa afectiva, donde luego de poner cada uno su nombre en una tarjeta y, sentados en un maagal, estas se pasaban de mano en mano al sonido de la música. Al detenerse, debían buscar a la persona cuyo nombre tenían, y desearle algo por estos años de estudio juntos.

Las festividades y conmemoraciones no fueron una unidad temática ajena al tema y objetivos propuestos en este segundo período. De esta manera, cuando tuvo lugar la celebración de la fiesta de $T u$ bishvat ${ }^{21}$, seleccionamos varias dinámicas mediante las que los talmidim conocieron árboles famosos para el pueblo hebreo y la tierra de Israel, su relación con algunos valores del judaísmo e indagamos en su posible conexión con acciones realizadas por ellos en la comunidad y en sus vidas.

El Día Internacional de la Memoria de la Víctimas del Holocausto declarado por la Asamblea General de la ONU, el Majón se unió a la campaña internacional \#WeRemember y la kitá escenificó 3 de los momentos sobre la memoria de la $S h o a^{22}$ : la negación a hablar del tema por parte de los sobrevivientes; la recopilación y divulgación de los testimonios de los protagonistas; y el compromiso y la responsabilidad de las nuevas generaciones de no olvidar lo sucedido.

En Pesaj ${ }^{23}$, el Majón realiza un seder educativo. En este, nuestros talmidim tuvieron a su cargo la explicación de la keará ${ }^{24}$. Con el deseo de que resultara divertida e instructiva, se representó una escena en un hogar judío cubano donde, el día de la preparación de la cena, la madre enfrentaba el conflicto de no tener todos los ingredientes necesarios y habérsele roto el plato ritual. Poco a poco, los familiares y amigos aparecían para ayudarla a encontrar soluciones, pues lo principal era mantener el principio de ledor vador ${ }^{25}$ y el compromiso de mantener un hogar judío.

\footnotetext{
${ }^{20}$ Nota del Editor: Janucá conocida tambien como Jag Urim , Fiesta de las luminarias conmemora la victoria de los macabeos sobre los griegos seléucidas y la rededicación del templo de Jerusalen al culto del Dios de Israel.

${ }^{21}$ Nota del Editor: Tu bishvat, festividad judía conocida como Año nuevo de los árboles.

${ }^{22}$ Nota del Editor: Shoá, Holocausto.

${ }^{23}$ Nota del Editor: Pésaj, fiesta que conmemora la salida de los israelitas de Egipto.

${ }^{24}$ Nota del Editor: keará, fuente en la que se colocan los alimentos imbólicos a concumir duante la festividad de Pésaj.

${ }^{25}$ Nota del Editor: ledor vador, frase hbr bíblica significa de generacion en generación.
} 
Al mirar atrás, varias son las conclusiones que podríamos exponer sobre este curso lectivo, no obstante, para nosotras, lo más significativo ha sido la transformación de todos, así como nuestro crecimiento, logro obtenido gracias a los caminos y retos de la educación. En los tiempos actuales, se sigue evidenciando el conflicto descrito por José Martí en 1892:

De todo el Norte, más famosas que otras de más utilidad, son las universidades de Harvard y de Yale, que en todo creen deber estar de punta, desde regatas hasta certámenes públicos, cuando lo que se ha de ver en los colegios no es el modo de alzar a unos contra otros, ni perder la actividad en competencias entre hermanos, ni aguzar en la carne propia las armas que solo se han de esgrimir en caso de gran necesidad contra la ajena, ni avivar el espíritu de secta y bandería que quiere freno más que espuela en el hombre. Criar amor debiera ser la función de los colegios, y no robustecerse el pie para zarandearle a Harvard los remos invencibles. Y este es punto grave, sobre si debe la educación afilarle el diente al hombre, por la teoría de que ve la vida como una mesa puesta, donde gana el mejor puesto quien sabe dar más dentelladas; o si ha de tener la educación, reconociendo la suma de competencia que funge en el mundo junto con el poder de unión, a buscar la defensa contra la agresión en el aminoramiento de esta por los hábitos fraternales de la cultura: sobre si se le fomenta la bestia al hombre, o se le reduce. ${ }^{26}$

Es este entonces un viejo asunto, hoy en manos no solo de maestros, sino de la familia, decisores, políticos e instituciones sociales, etc. Reformulamos nuevamente nuestras interrogantes: ¿qué tipo de hombre queremos formar? ¿En qué medida la educación puede contribuir a ello? Siendo martianas, advertimos la temprana formación sentimental de este pensador, su interés y compasión por el otro. Luego, su decisión de actuar, de educar, de amar. Salto de fe en el mejoramiento humano, deseo íntimo traducido en hechos para con el colega, el compañero, el amigo, el hijo.

Educar es nobleza; traer a la luz lo escondido; creer en el otro; incidir en él; hermanar; humanizar. Del judaísmo seleccionamos la siguiente frase, pues tal pareciera una máxima que acompañara la vida de nuestro José Martí: "Si no soy para mí mismo, ¿quién será [para mí]?, y si yo soy [sólo] para mí, ¿qué soy? “27 Reorientamos: si las diferentes técnicas empleadas posibilitaron que nuestros talmidim tuvieran un rol activo, actuaran con independencia y fueran decisores de las actividades; si salieron de su espacio individual e incidieron en el comunitario; si primó el ambiente de respeto, de escucha, de cooperación, de alegría, de apoyo entre todos; si, a pesar de los obstáculos cotidianos, se mantuvo el deseo de volver cada domingo a la kitá Pardés Alef a aprender y a divertirse, creemos: este acto profundo de fe ha sido retribuido. Juntos hemos hecho camino.

\footnotetext{
${ }^{26}$ Martí, José. Carta de José Martí. Obras escogidas en tres tomos. Colección de textos martianos, La Habana, Ciencias Sociales, 2000 pp.71-72

27 Tomado de El individuo frente a las necesidades de la comunidad. Responsabilidad mutua. Amiut iehudit. Material digital de la Fundación BAMA.
} 


\section{Referencias bibliográficas}

Inerarity Rojas, María de la Caridad (comp.) (2017). Técnicas participativas. La Habana: Caminos.

Martí, José. (2000). Carta de José Martí. Obras escogidas en tres tomos. Colección de textos martianos. La Habana: Ciencias Sociales.

Martí, José. (2007). Ismaelillo, tomado de Poesía completa. La Habana: Letras Cubanas.

Martí, José (1959). La edad de oro. La Habana: Gente Nueva.

Motola Pedroso, Patricia y Tamara Kely Martino Zagovalov (2018). Caminos de la educación judía en Cuba. Espacio laical no. 3. 68-73

Rosen, Sara (2007). Phonetic Hebrew Decoding. www.hebrewreading.com 